\title{
Low Temperature Hybrid Mars Ascent Vehicle Concept Development and Planning at MSFC
}

\author{
George Story ${ }^{1}$, Andrew Prince ${ }^{2}$, Jessica Chaffin ${ }^{3}$, John Dankanich $^{4}$, Tim Kibbey ${ }^{5}$ \\ Marshall Space Flight Center \\ \& Ashley $\operatorname{Karp}^{6}$
}

Jet Propulsion Laboratory, California Institute of Technology

Return of samples from Mars has been a goal of NASA's for decades. The current Mars Sample Return mission concepts have a multiple launch rocket from the earth, where one mission delivers a caching rover to collect and package the Martian soil samples. Another rocket sends the Mars Ascent Vehicle that takes those samples to orbit. Another rocket sends an orbiter, that also meets up with the samples in orbit, and brings them back to earth. Our tasks have been focused on the Mars Ascent Vehicle. To leave the Martian surface, it requires a two burn trajectory, one to get off the planet and another to circularize the orbit. Recent studies have led to the investigation of a hybrid rocket solution. That technology has been under development for several years ${ }_{2}^{1}, 2,3,4,4,6,7$. This paper will discuss some of the work going on at MSFC to understand how to process the fuel, some test firings done to characterize some design features and some planning done to scope out what it would take to qualify a hybrid rocket motor for this application[Depending on length, etc, this may move to Ashley's paper ${ }^{8}$ ].

\section{Fuel Processing}

The baseline design for the Mars Ascent Vehicle, coming out of the Point of Departure review in December $2016^{9}$ was a Mixed oxides of Nitrogen oxidizer and SP7, a paraffin based fuel. SP7 was developed by Space Propulsion Group (SPG) (reference) to handle the temperature extremes seen on Mars ${ }^{10}$. The longer the rocket can handle the cold cycles without requiring heat, the more science that can be done since that energy won't be required to keep the MAV warm. Thermal cycling testing has been done on representative samples and the fuel survived, however there was some debonding of the fuel to case ${ }^{11}$. Flexible cold temperature insulation materials are needed and is an area of future work.

In the planning for the 2017 round of testing with vendors, it was decided to have MSFC update the SP7 processing and have MSFC provide the fuel for the tests of record to the vendors. The vendors were doing full scale testing of the MAV design. SPG and Whittinghill Aerospace have been doing testing in Butte, Montana and Mojave, California respectively ${ }^{8}$. This paper will discuss the process development in going

\footnotetext{
${ }^{1}$ Solid Propulsion Engineer, MSFC Solid Propulsion System, ER52 AIAA Member

2 Solid Propulsion Engineer, MSFC Solid Propulsion System, ER51 AIAA Member

${ }^{3}$ Solid Propulsion Engineer, MSFC Solid Propulsion System, ER51 AIAA Member

${ }^{4}$ What is John's title?

${ }^{5}$ Solid Propulsion Engineer, Jacobs Engineering, AIAA Member

${ }^{6}$ Propulsion Engineer, JPL Propulsion and Fluid Flight Systems, M/S 125-211, AIAA Member
} 
from early development melting (Figure 1) to large mixers, from hockey pucks to monolithic grains (Figure 2).

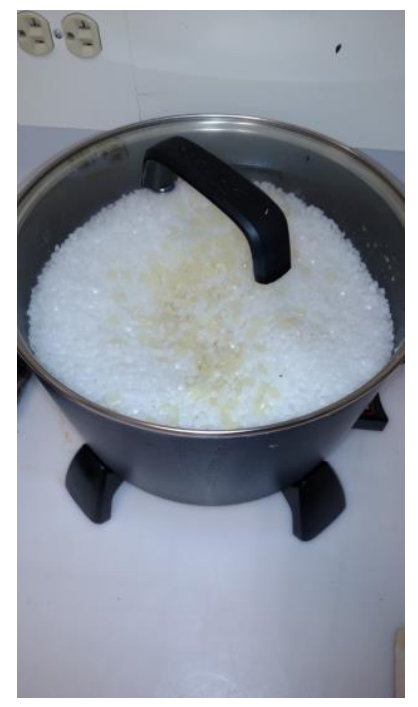

Figure 1 Early Melting attempts

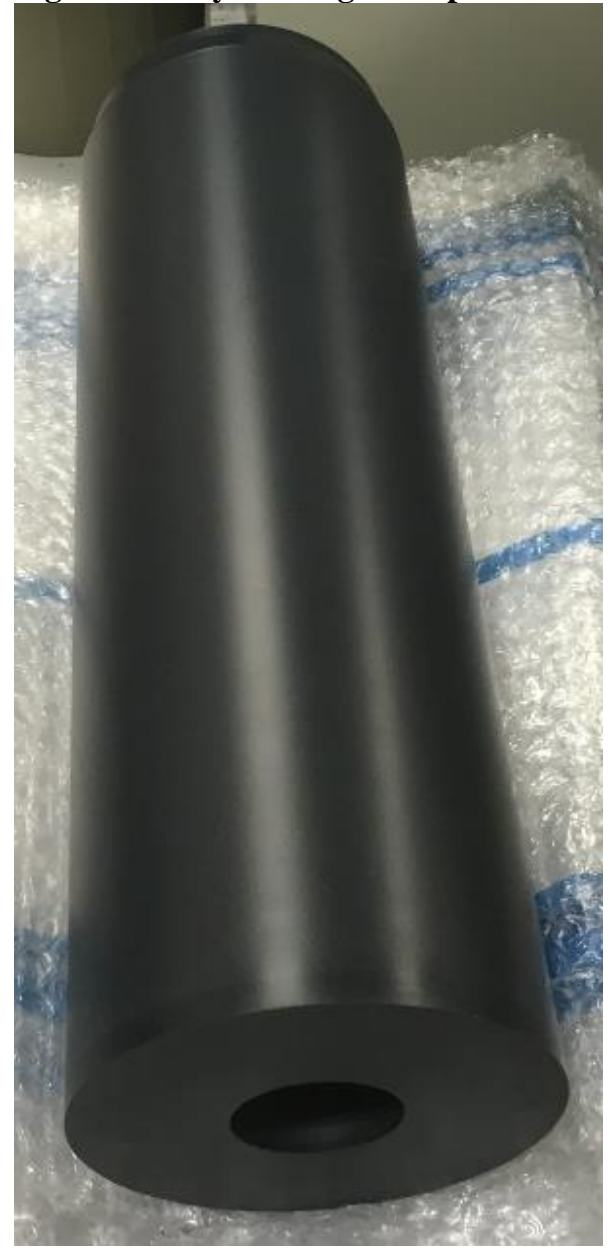

Figure 2 Monolithic Grain 
II Solid fuel tests

After the thermal testing was complete $\frac{12}{12}$, it was noted that the Coefficient of thermal expansion effects on the grain would be the worst in the longest dimensions. It was proposed that instead of stress relief flaps used in solid rocket motors, a segmented grain would be used. The grain interfaces might change how the grains reacted. A test program was developed based on the readily available solid fuel torch hardware (reference), using oxygen as the oxidizer instead of MON3.

III Qualification testing planning

A planning exercise was done to scope out what it would take to qualify a hybrid rocket motor for this application. This topic will be covered here or there ${ }^{8}$. 
${ }^{1}$ Ashley C. Karp, Barry Nakazono, Robert Shotwell, Joel Benito, David Vaughan, and George T. Story. "Technology Development Plan and Preliminary Results for a Low Temperature Hybrid Mars Ascent Vehicle Concept", 53rd AIAA/SAE/ASEE Joint Propulsion Conference, AIAA Propulsion and Energy Forum, (AIAA 2017-4900)

${ }^{2}$ Ashley C. Karp, Barry Nakazono, Joel Benito Manrique, Robert Shotwell, David Vaughan, and George T. Story. "A Hybrid Mars Ascent Vehicle Concept for Low Temperature Storage and Operation", 52nd AIAA/SAE/ASEE Joint Propulsion Conference, AIAA Propulsion and Energy Forum, (AIAA 20164962)

${ }^{3}$ R. Shotwell, J. Benito, A. Karp and J. Dankanich, "A Mars Ascent Vehicle for potential mars sample return," 2017 IEEE Aerospace Conference, Big Sky, MT, 2017, pp. 1-12.

doi: 10.1109/AERO.2017.7943851

URL: http://ieeexplore.ieee.org/stamp/stamp.jsp?tp=\&arnumber=7943851\&isnumber=794355

$\underline{4}$

${ }^{4}$ A. Karp et al., "A hybrid mars ascent vehicle design and FY 2016 technology development," 2017 IEEE Aerospace Conference, Big Sky, MT, 2017, pp. 1-10.

doi: 10.1109/AERO.2017.7943948,

URL: http://ieeexplore.ieee.org/stamp/stamp.jsp?tp=\&arnumber=7943948\&isnumber=794355

$\underline{4}$

5 J. Benito et al., "Hybrid propulsion Mars Ascent Vehicle concept flight performance analysis," 2017 IEEE Aerospace Conference, Big Sky, MT, 2017, pp. 1-13.

URL: http://ieeexplore.ieee.org/stamp/stamp.jsp?tp=\&arnumber=7943964\&isnumber=794355 $\underline{4}$

${ }^{6}$ R. Shotwell, J. Benito, A. Karp and J. Dankanich, "Drivers, developments and options under consideration for a Mars ascent vehicle," 2016 IEEE Aerospace Conference, Big Sky, MT, 2016, pp. 1-14.

doi: 10.1109/AERO.2016.7500822

URL: http://ieeexplore.ieee.org/stamp/stamp.jsp?tp=\&arnumber=7500822\&isnumber=750049 $\underline{6}$

${ }^{7}$ A. C. Karp et al., "Technology development and design of a hybrid Mars ascent vehicle concept," 2016 IEEE Aerospace Conference, Big Sky, MT, 2016, pp. 1-10.

doi: 10.1109/AERO.2016.7500835

URL: $\underline{\text { http://ieeexplore.ieee.org/stamp/stamp.jsp?tp=\&arnumber }=7500835 \& \text { isnumber }=7500496}$

${ }^{8}$ Ashley Chandler Karp, Barry Nakazono, David Vaughan, George Story, Britt Oglesby , \& Andrew Prince. "Update on Technology Development Plan for a Low Temperature Hybrid Mars Ascent Vehicle Concept", 54 ${ }^{\text {th }}$ AIAA/SAE/ASEE Joint Propulsion Conference, AIAA Propulsion and Energy Forum, (pending...) 
${ }^{9}$ A. Karp et al., "A hybrid mars ascent vehicle design and FY 2016 technology development," 2017 IEEE Aerospace Conference, Big Sky, MT, 2017, pp. 1-10.

doi: 10.1109/AERO.2017.7943948,

URL: http://ieeexplore.ieee.org/stamp/stamp.jsp?tp=\&arnumber=7943948\&isnumber=7943554

${ }^{10}$ Brian Evans, Arif Karabeyoglu, "Development and Testing of SP7 Fuel for Mars Ascent Vehicle Application" ", 53rd AIAA/SAE/ASEE Joint Propulsion Conference, AIAA Propulsion and Energy Forum, (AIAA 2017-4831)

${ }^{11}$ Edgardo Farias, Matthew Redmond, Ashley Karp, Robert Shotwell, George Story, "Thermal Cycling for Development of Hybrid Fuel for a Notional Mars Ascent Vehicle", 52nd AIAA/SAE/ASEE Joint Propulsion Conference (AIAA 2016-4563)

${ }^{12}$ Edgardo Farias, Matthew Redmond, Ashley C. Karp, Robert Shotwell, Flora S. Mechentel, and George T. Story. "Thermal Cycling for Development of Hybrid Fuel for a Notional Mars Ascent Vehicle", 52nd AIAA/SAE/ASEE Joint Propulsion Conference, AIAA Propulsion and Energy Forum, (AIAA 20164563) 